\title{
Mandibular Reconstruction in Cervical Desmoid Tumors
}

\author{
Ayoub Boutahar*, Imane Oualili, Abdelhalim Mahmoudi, Khalid Khattala, Youssef Bouabdallah \\ Department of Pediatric Surgery, Faculty of Medicine and Pharmacy of Fez, University Hospital Center Hassan II, Fes, Morocco \\ Email: *ayoub.boutahar@usmba.ac.ma
}

How to cite this paper: Boutahar, A., Oualili, I., Mahmoudi, A., Khattala, K. and Bouabdallah, Y. (2021) Mandibular Reconstruction in Cervical Desmoid Tumors. Open Journal of Pediatrics, 11, 398-405. https://doi.org/10.4236/ojped.2021.113037

Received: June 27, 2021

Accepted: August 30, 2021

Published: September 2, 2021

Copyright $\odot 2021$ by author(s) and Scientific Research Publishing Inc. This work is licensed under the Creative Commons Attribution International License (CC BY 4.0).

http://creativecommons.org/licenses/by/4.0/

(c) (i) Open Access

\begin{abstract}
Introduction: Desmoid tumors are benign soft tissue tumors, but their infiltration character is responsible for big morbidity, especially in the cervicofacial location. Their management, therefore, represents a real challenge. Clinical case: Reporting a case of a 4-year-old girl presenting a desmoid tumor at the expense of the mandibular corpus and the right ascending ramus, with loco-regional infiltration, and whose treatment consisted of surgical resection of the tumor with Hemi-mandibulectomy and reconstruction according to the Masquelet technique. Conclusion: The traditional treatment consists of a large local excision with negative surgical margins. Head and neck fibromatosis, while rare, present a complex problem as they are often aggressive, and invade local bone, nerve and muscles, and can leave patients with a cosmetic deformity. In our case, it was a mandibular reconstruction after a large resection of a desmoid tumor with a location on the head and neck. With good consolidation, absence of recurrence, and without aesthetic sequelae at the control.
\end{abstract}

\section{Keywords}

Desmoid Tumor, Fibromatosis, Surgery, Masquelet

\section{Introduction}

Desmoid tumors, or aggressive fibromatosis, are soft tissue tumors [1].

It is a fibroblastic proliferation of cells that arises from the musculoaponeurotic tissues of the body. Microscopically benign but can be locally invasive with a tendency to recur locally after resection [2] [3], without potential for metastasis.

According to the location of occurrence, desmoid tumors are classified into 3 types: intra-abdominal, abdominal, and extra-abdominal types. Extra-abdominal 
desmoid tumors comprise a third of all desmoid tumors and usually occur in the shoulder, pelvic girdle, and limbs. Only $10 \%$ to $25 \%$ of extra-abdominal desmoid tumors develop in the head and neck region.

Among them, the neck is the most common site of occurrence, followed by the face, oral cavity, scalp, and paranasal sinus [4].

In children, it typically presents as a painless, firm, possibly rapidly enlarging mass, fixed to underlying bone and soft tissue.

The management of cervico-facial locations represents a real challenge. When this lesion occurs in the head and neck, the proximity of vital structures and the complexity of fascial planes often preclude complete resection.

In this work, we describe the contribution of the Masquelet induced-membrane technique, allowing the reconstruction of bone substance losses in large resections necessary for surgery.

\section{Observations}

A 4-year-old girl presented with a 3-month history of a right submandibular mass, with no significant medical or surgical history, and she did not incur any previous trauma to that area.

On physical exam, the mass was firm, fixed, and with no inflammatory signs in sight.

In tomodensitometry (Figure 1), the osteolytic tissue mass is dependent on the mandibular body and the right ascending ramus. Hypodense and raised heterogeneously. And do not turn intense after injection; it measures $5 \times 6 \times 4.7$ $\mathrm{cm}$.

Inside, the mass is in contact with the digastric and mylo-hyoid muscles with loss of the fatty border of the separation, it pushes back the trachea and the submaxillary gland without invading it; it is also in contact with the thyroid cartilage without signs of lysis or condensation latter.

At the top, the mass lyses the mandibular ramus with speculated periosteal reaction; with infiltration of the base of the tongue.

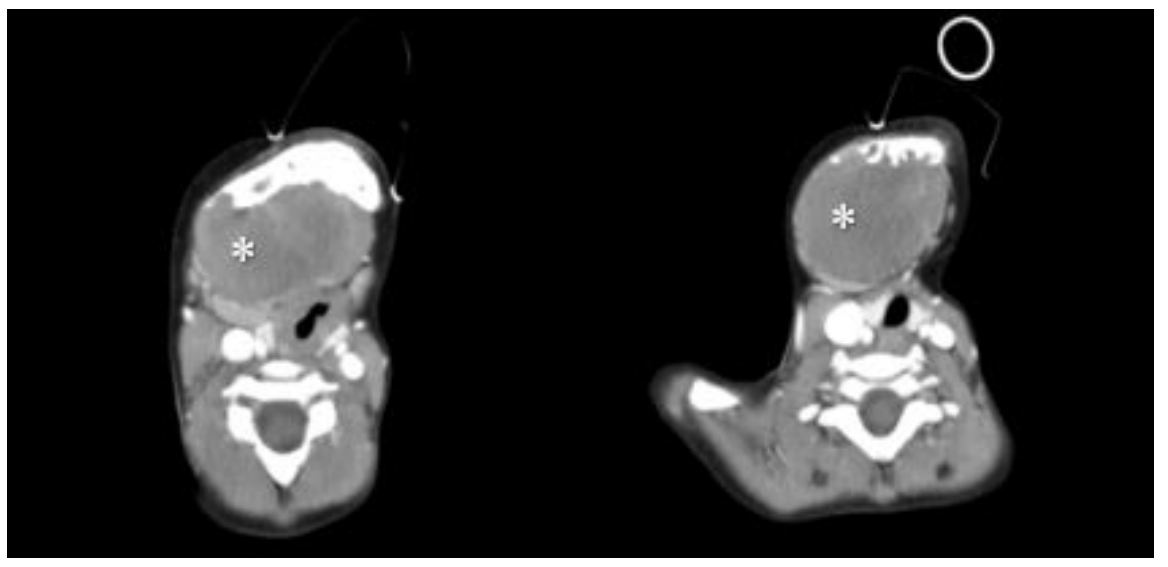

Figure 1. Axial computed tomography: the osteolytic tissue mass is dependent on the mandibular body and the right ascending ramus. $\left({ }^{*}\right)$ represents mass. 
A biopsy of the lesion was performed. The histological study showed a mesenchymal tumor proliferation with little cellularity, arranged in layers, and short bundles on a collagenous background. The tumor cells are fusiform, with regular nuclei, fine chromatin and poorly limited eosinophilic cytoplasm without mitosis or necrosis.

In immunohistochemical study, tumor cells express AML, they do not express desmin, myogenin CD34 or PS100.

Anatomopathologists concluded that that it was a desmoid fibromatosis.

The treatment was the removal of the tumor mass with hemi-mandibulectomy and reconstruction using the Masquelet induced-membrane technique (IMT).

In the first stage, a 16/10 pin was placed between the two ends of the mandibular bone. Once fixation has been achieved, the defect was filled with a cement spacer. It is important to fill the whole defect with the spacer, from bone end to bone end (Figure 2).

The second stage procedure was performed 9 weeks after the first.

The surgical site was approached through the previous incision and careful dissection until the bio-active membrane is identified and then it is incised carefully so as not to damage the capsule.

The cement spacer was then removed.

Bone graft (Cancellous bone harvested from the left iliac crest) was then placed to fill the entire defect. The bio-membrane was closed with an absorbable Vicryl suture.

During follow-up, the wound was healed without clinical deformation of the mandible. A control CT-scan was performed, there was a filling of the grafted bone with no tumor residue (Figure 3 ).

\section{Discussion}

No general guidelines are available on the management of pediatric aggressive fibromatosis based on studies in large cohorts [5].

Desmoid tumors represent less than $0.03 \%$ of all tumors [6] and about $3.5 \%$ of fibrous tumors [7].

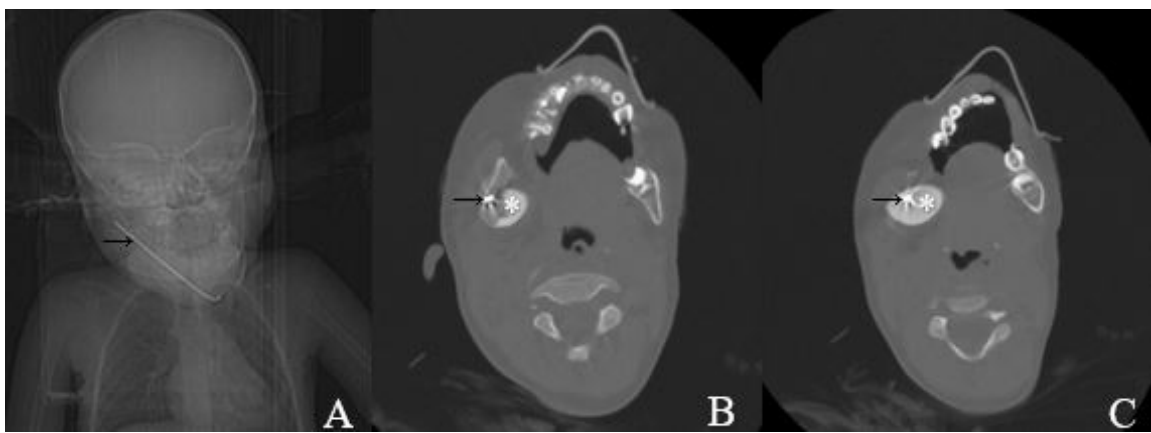

Figure 2. (A) - Post-operative control radiography: pin in place. (B), (C)—Control CT-scan: No mass syndrome or contrast at right mandibular stump, Osteosynthesis material in place. $\left(^{\star}\right)$ represents cement spacer; $(\rightarrow)$ represents pin. 


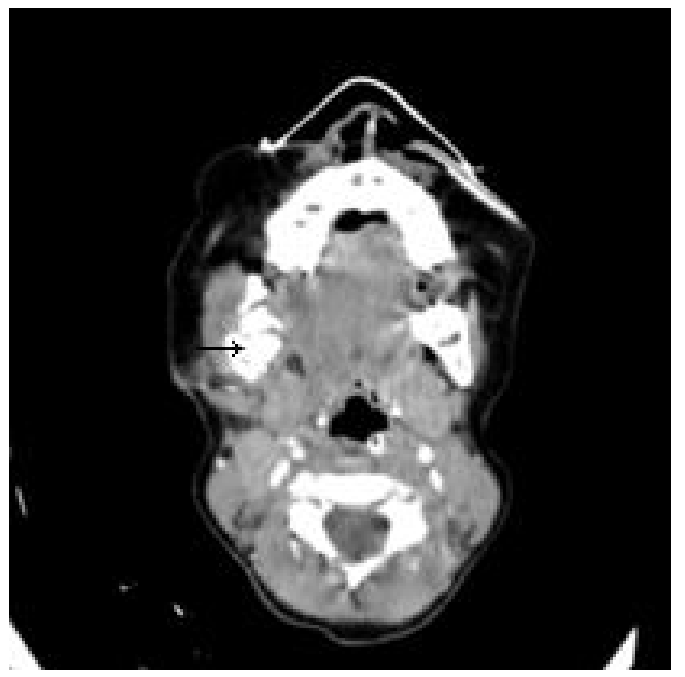

Figure 3. Control CT-scan after second stage of Masquelet: no tumor residue, and visualization of the bone graft in place. $(\rightarrow)$ represents Bone graft.

Infantile fibromatosis is the pediatric counterpart to fibromatosis [8]. This lesion presents between birth and 8 years of age, most commonly in the first 2 years of life.

Infantile fibromatosis often involves the muscles of the head and neck, shoulder, and upper arm.

In a review of literature conducted by Babin et al. 54 cases of cervical desmoid tumors from 1980 to 1998 [9], the face is the most common location (50 cases) including 15 in the submento-mandibular region, ten in the tongue, ten in the nasal and paranasal cavities, eight in the mandible, five in the oral cavity, one in the parotid region and one in the retro-auricular region [10].

Only four cervicomediastinal locations are described.

According to Siegel and Bradford, the cervicofacial locations are, in order of frequency: tongue, mandible, maxilla, and mastoid [2].

The precise etiology is unknown; trauma, genetic and hormonal factors may all play a part.

It appears that tumor growth may be oestrogen dependent as spontaneous regression has been described at the menarche and menopause [11].

However, its occurrence is also seen in hereditary syndromes such as familial adenomatous polyposis (FAP), hereditary desmoid disease (HDD) and familial infiltrative fibromatosis (FIF) [12].

Clinically, the lesion generally presents as a mass of recent appearance, poorly limited, slow growth, with little or no sensitivity [13]. The development of such a lesion in the cervicofacial region, which is characterised by many functional structures and specially those essential to aerodigestive functions, can lead to functional deficits (vision, chewing, swallowing, etc.) [14] [15], nervous compressions [9] [16], or even a life-threatening condition.

The scanner and especially magnetic resonance imaging (MRI) are the radio- 
logical examinations of choice. They allow us to appreciate the limits of the tumor and its relationship with the vasculo-nervous package [17].

The diagnosis of aggressive fibromatosis is based on histology, and it arises principally from the connective tissue of muscle and the overlying fascia (aponeurosis). Characteristically, aggressive fibromatosis is circumscribed poorly and infiltrates the surrounding tissue, which usually is striated musculature.

Microscopically, aggressive fibromatosis has spindle-shaped fibroblast-like cells without atypia, surrounded by abundant collagen, with rare mitoses and no necrosis.

Distinction of aggressive fibromatosis from other spindle-cell fibroblastic proliferations, such as nodular fasciitis, reactive fibrosis, low-grade fibrosarcoma, malignant fibrous histiocytoma and malignant schwannoma, can be difficult. In general, pronounced cellular atypia, pleomorphism, high mitotic activity and abundant necrosis are not seen in aggressive fibromatosis [18].

The mainstay of treatment for aggressive fibromatosis is definitive surgery with clear margins [19].

Desmoid tumors must be removed together with normal tissue resection margins, because tumor cells always infiltrate into adjacent deep structure, and the true extent is always beyond the surgeon's ability and judgment during operation [4].

It is generally agreed that wide excision is the treatment of choice and where the mandible is involved, this will include the affected bone as a partial mandibulectomy. More extensive lesions may require a hemi-mandibulectomy. As the underlying pathology is benign, immediate reconstruction can be undertaken using rib or iliac bone.

This will limit the deformity and adverse effect on growth in young children [20].

In a review of literature conducted by A. Khaladj-Ghom et al. Reconstruction was discussed at length, and a decision was made to defer definitive bony reconstruction because of growth concerns and lack of an adequate anatomic replacement for the mandibular ramus at this age. The defect was temporarily reconstructed using a mandibular reconstruction plate and condylar prosthesis [21].

In our case, the treatment was the removal of the tumor mass with hemimandibulectomy. The defect was reconstructed using the Masquelet inducedmembrane technique (IMT).

The technique comprises 2 surgical stages. In the first stage, a cement spacer is placed into the bone defect. 9 weeks later, the cement is removed and the cavity formed by the induced-membrane is filled up with bone graft. Corticalization of the reconstructed bone segment is acquired in a few months.

During follow-up, there was a filling of the grafted bone with no tumor residue, and no adjuvant therapy has been given.

Because desmoid tumors of the head and neck frequently entrap important 
neurovascular structures, complete resection of these tumors is sometimes difficult and adjuvant management is anecdotally suggested for adequate local control. However, the role of adjuvant management has not been established because spontaneous regression and arrested growth after incomplete resection are occasionally observed, and the section margin is poorly correlated with the development of local recurrence [4].

Adjuvant therapy, such as chemotherapy, radiation therapy, and hormonal therapy are occasionally given for persistent disease, recurrent disease, or unresectable disease. Adjuvant therapy is rarely given as a primary therapy for aggressive fibromatosis, and there is little evidence to support its use [22] [23].

\section{Conclusion}

Aggressive fibromatosis remains a difficult disease to treat. Aggressive surgical resection, with an attempt at negative margins is the standard treatment. Head and neck fibromatosis, while rare, present a complex problem as they are often aggressive, and invade local bone, nerve and muscles, and can leave patients with a cosmetic deformity.

\section{Conflicts of Interest}

The authors declare no conflicts of interest regarding the publication of this paper.

\section{Patient Consent}

Consent to publish the case report was not obtained. This report does not contain any personal information that could lead to the identification of the patient.

\section{Authorship}

All authors attest that they meet the current ICMJE criteria for Authorship.

\section{References}

[1] Mignot, L. (2002) Les tumeurs desmoïdes. Orphanet encyclopédie, janvier.

[2] Siegel, N.S. and Bradford, C.R. (2000) Fibromatosis of the Head and Neck: A Challenging Lesion. Otolaryngology_Head and Neck Surgery, 123, 269-275. https://doi.org/10.1067/mhn.2000.107456

[3] Fayçal, O., Lamia, G., Sonia, M., Karima, M., Mahmoud, S., Samir, B., et al. (2005) Place des thérapeutiques médicales dans la prise en charge des tumeurs desmoïdes de l'enfant. Journal de Pédiatrie et de Puériculture, 18, 62-68. https://doi.org/10.1016/j.jpp.2005.01.002

[4] Wang, C.P., Chang, Y.L., Ko, J.Y., Cheng, C.H., Yeh, C.F. and Lou, P.J. (2006) Desmoid Tumor of the Head and Neck. Head Neck, 28, 1008-1013. https://doi.org/10.1002/hed.20467

[5] Meazza, C., Bisogno, G., Gronchi, A., et al. (2010) Aggressive Fibromatosis in Children and Adolescents. Cancer, 116, 233-240.

[6] Shields, C.J., Winter, D.C., Kirwan, W.O. and Redmond, H.P. (2001) Desmoid 
Tumours. European Journal of Surgical Oncology, 27, 701-706.

https://doi.org/10.1053/ejso.2001.1169

[7] Cotte, E., Glehen, O., Monneuse, O., Cotton, F. and Vignal, J. (2004) Tumeurs desmoïdes associées à la polypose adénomateuse familiale. Gastroentérologie Clinique et Biologique, 28, 574-581. https://doi.org/10.1016/S0399-8320(04)95014-2

[8] Enzinger, F.M. and Weiss, S.W. (1995) Soft Tissue Tumors. 3rd Edition, Mosby, St Louis.

[9] Babin, E., Goullet de Rugy, M., Moreau, S., Comoz, F., Bourdon, N., Roquier, V., et al. (2000) Tumeur desmoïde cervico-faciale de l'enfant: A propos d'un cas et revue de la littérature. Annales d oto-laryngologie et de chirurgie cervico faciale, 117, 118-125.

[10] Bouguila, J., Khonsari, R.H., Zitouni, K., Zairi, I. and Adouani, A. (2012) La fibromatose agressive faciale chez l'enfant: Une localisation fréquente d'une tumeur exceptionnelle! Annales de Chirurgie Plastique Esthétique, 57, 304-307. https://doi.org/10.1016/j.anplas.2009.12.005

[11] Tostevin, P.M.J., Wyatt, M. and Hosni, A. (2000) Six Cases of Fibromatosis of the Head and Neck in Children. International Journal of Pediatric Otorhinolaryngology, 53, 235-244. https://doi.org/10.1016/S0165-5876(00)82013-3

[12] Lips, D.J., Barker, N., Clevers, H. and Hennipman, A. (2009) The Role of APC and Beta-Catenin in the Aetiology of Aggressive Fibromatosis (Desmoid Tumors). European Journal of Surgical Oncology, 35, 3-10. https://doi.org/10.1016/j.ejso.2008.07.003

[13] Jeblaoui, Y., Bouguila, J., Haddad, S., Helali, M., Zairi, I., Zitouni, K., et al. (2007) Fibromatose Agressive Mandibulaire. Revue de Stomatologie et de Chirurgie Maxillo-faciale, 108, 153-155. https://doi.org/10.1016/j.stomax.2006.05.003

[14] Amerasinghe, N., Rogers, S., Rowlandson, K.J. and Hodgkins, P. (2006) Fibromatosis (Desmoid Tumor) Involving the Orbit and Cheek. Journal of AAPOS, 10, 479-481. https://doi.org/10.1016/j.jaapos.2006.04.008

[15] Roychoudhury, A., Parkash, H., Kumar, S. and Chopra, P. (2002) Infantile Desmoid Fibromatosis of the Submandibular Region. Journal of Oral and Maxillofacial Surgery, 60, 1198-1202. https://doi.org/10.1053/joms.2002.35034

[16] Dequanter, D. and Gebhart, M. (2002) Tumeurs desmoïdes. Journal de Chirurgie, 139, 236-239.

[17] Faulkner, L.B., Hajdu, S.I., Kher, U., La Quaglia, M., Exelby, P.R., Heller, G., et al. (1995) Pediatric Desmoid Tumor: Retrospective Analysis of 63 Cases. Journal of Clinical Oncology, 13, 2813-2818. https://doi.org/10.1200/JCO.1995.13.11.2813

[18] Plukker, J.T., Van Oort, I., Vermey, A., Molenaar, I., Hoekstra, H.J., Panders, A.K., et al. (1995) Aggressive Fibromatosis (Non-Familial Desmoid Tumor): Therapeutic Problems and the Role of Adjuvant Radiotherapy. British Journal of Surgery, 82, 510-514. https://doi.org/10.1002/bjs.1800820424

[19] Pena, S., Brickman, T., StHilaire, H. and Jeyakumar, A. (2014) Aggressive Fibromatosis of the Head and Neck in the Pediatric Population. International Journal of Pediatric Otorhinolaryngology, 78, 1-4. https://doi.org/10.1016/j.ijporl.2013.10.058

[20] Carr, R.J., Zaki, G.A., Leader, M.B. and Langdon, J.D. (1992) Infantile Fibromatosis with Involvement of the Mandible. British Journal of Oral and Maxillofacial Surgery, 30, 257-262.

[21] Khaladj-Ghom, A., Isaiah, A., Caccamese, J. and Pereira, K.D. (2020) Facial Desmoid Tumor in a 2-Year-Old. Ear, Nose \& Throat Journal, 99, NP3-NP5. https://doi.org/10.1177/0145561318823647 
[22] Sharma, A., Ngan, B.Y., Sandor, G., Campisi, P. and Forte, V. (2008) Pediatric Aggressive Fibromatosis of the Head and Neck: A 20-Year Retrospective Review. Journal of Pediatric Surgery, 43, 1596-1604.

https://doi.org/10.1016/j.jpedsurg.2008.02.001

[23] Buitendijk, S., van de Ven, C.P., Dumans, T.G., et al. (2005) Pediatric Aggressive Fibromatosis: A Retrospective Analysis of 13 Patients and Review of Literature. Cancer, 104, 1090-1099. https://doi.org/10.1002/cncr.21275. 